\title{
Does transfusion of blood and blood products increase the length of stay in hospital?
}

\author{
Ayten Saraçoğlu', Mehmet Ezelsoy², Kemal Tolga Saraçoğlu' \\ Department of Anesthesiology and Intensive Care', Cardiovascular Surgery², \\ Istanbul Bilim University Medical School, Turkey
}

Background and goals:

Blood and blood products are still frequently used in cardiac surgeries despite the implementation of protection strategies against transfusion. According to the guidelines published by the American Society of Cardiothoracic

Anesthesia, the use of cell saver is the class I recommendation for all patients who have infection or malignancy and undergo cardiac surgery.

The quality- and material-related adverse effects caused by extended hospital stay have become more important today than ever before. The length of hospitalization after routine procedures has been specified as a measure of quality to reduce cost and hospital-acquired morbidity (7). However, there is less data specifically related to the cardiac surgery patients. In this retrospective study, we aimed to analyze the use of blood and blood products in cardiac surgeries and to investigate its effect on clinical outcomes.

\section{Methods:}

Following the Ethics Committee approval, patients who had open heart surgery at our clinic for coronary bypass and/or heart valve repair between 2006 and 2016 were included in our study. Perioperative transfusion requirements were noted. Also, patients were evaluated regarding survival, complication rates and the duration of hospitalization. Patients were divided into two groups considering the duration of hospital stay and the duration of the stay at the intensive care unit.

Table I: The parameters affecting ICU stay more than 2 days

\begin{tabular}{|c|c|c|c|c|c|c|c|}
\hline & & \multicolumn{2}{|c|}{ ICU stay $\leq 2$ days } & \multicolumn{2}{|c|}{ ICU stay $>2$ days } & \multirow{2}{*}{\multicolumn{2}{|c|}{ p }} \\
\hline & & mediantsd/n(x) & Median & median $t 5 d / n(\%)$ & Median & & \\
\hline \multicolumn{2}{|l|}{ Age } & $67,4 \pm 9,9$ & 68,0 & $65,3 \pm 9,2$ & 65,0 & 0,420 & \pm \\
\hline \multirow{2}{*}{ Gender } & Female & $40(40,0 \%)$ & & $9(52,9 \times)$ & & \multirow{2}{*}{0,317} & \\
\hline & Male & $50(60,0 \%)$ & & $8(47,166)$ & & & \\
\hline \multicolumn{2}{|l|}{ BMI } & $26,7 \pm 1,8$ & 26,3 & $26,7 \pm 2,2$ & 26,0 & 0,985 & 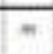 \\
\hline \multicolumn{2}{|c|}{ Cell Saver blood amount } & $740,0 \pm 222,0$ & 700.0 & $811,8 \pm 220,5$ & 800,0 & 0,163 & $m$ \\
\hline \multicolumn{2}{|l|}{ CBP TIME } & $118,9 \pm 54,8$ & 115,0 & $170,6 \pm 72,0$ & 180,0 & 0,004 & * \\
\hline \multicolumn{2}{|l|}{ Ox Time } & $81,2 \pm 33,5$ & 80,0 & $103,5 \pm 24,7$ & 100,0 & 0,004 & $n$ \\
\hline \multirow{2}{*}{ Cryoprecipitate } & Preoperative & $0,53 \div 2,45$ & 0,00 & $1,76 \pm 4,35$ & 0,00 & 0,136 & 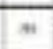 \\
\hline & Postoperative & $0,14 \pm 1,30$ & 0,00 & $1,06 \pm 2,33$ & 0,00 & 0,000 & $n$ \\
\hline \multirow{2}{*}{ FFP } & Preoperative & $3,47 \pm 3,42$ & 3,00 & $4,29 \div 2,85$ & 4,00 & 0,149 & $\pi$ \\
\hline & Postoperative & $0,70 \pm 2,21$ & 0,00 & $6,00 \pm 7,10$ & 3,00 & 0,000 & $n$ \\
\hline \multirow{2}{*}{ Platelet } & Preoperative & $3,12 \pm 5,59$ & 0,00 & $4,59: 6,26$ & 1,00 & 0,162 & $\pi$ \\
\hline & Postoperative & $0,60 \div 2,47$ & 0.00 & $3,4725,27$ & 0,00 & 0,001 & \# \\
\hline \multirow{2}{*}{ RBC } & Preoperative & $2,69 \div 3,77$ & 2,00 & $3,47 \pm 3,39$ & 3,00 & 0,196 & $m$ \\
\hline & Postoperative & $2,00 \pm 3,60$ & 1,00 & $11,47 \pm 16,04$ & 2.00 & 0,002 & $=$ \\
\hline \multirow{2}{*}{$\mathrm{Hb}$} & Preoperative & $12,4 \pm 2,2$ & 12,4 & $12,2 \pm 1,7$ & 12,3 & 0,798 & " \\
\hline & Postoperative & $10,7 \pm 1,2$ & 10,7 & $10,5 \pm 1,1$ & 10,6 & 0,626 & $n$ \\
\hline \multirow{2}{*}{ Htc } & Preoperative & $36,4 \pm 4,9$ & 36,6 & $35,0 \pm 4,3$ & 36,5 & 0,345 & $n$ \\
\hline & Postoperative & $31,2 \pm 3,3$ & 31,1 & $30,2 \pm 2,4$ & 30,1 & 0.233 & * \\
\hline \multirow{2}{*}{ INR } & Preoperative & $1,13 \pm 0,17$ & 1,10 & $1,34 \pm 0,58$ & 1,13 & 0,131 & * \\
\hline & Postoperative & $1,28 \pm 0,16$ & 1,25 & $1,34 \pm 0,30$ & 1,29 & 0,659 & $n$ \\
\hline \multirow{2}{*}{ BUN } & Preoperative & $19,8 \pm 8,1$ & 17,0 & $16,7 \pm 9,3$ & 15,0 & 0,063 & $=$ \\
\hline & Postoperative & $21,028,4$ & 19,0 & $19,2 \pm 6,9$ & 18,0 & 0.510 & $n$ \\
\hline \multirow{2}{*}{ Creatinine } & Preoperative & $0,98 \pm 0,26$ & 0,90 & $2,14 \pm 4,87$ & 0,90 & 0,800 & 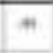 \\
\hline & Postoperative & $1,14 \pm 0,40$ & 1.00 & $1,14 \pm 0,42$ & 1,10 & 0,879 & n \\
\hline \multicolumn{2}{|l|}{ Bleeding volume } & $565,2 \pm 321,7$ & 490,0 & $849,4 \pm 392,6$ & 750,0 & 0,003 & $\overline{-}$ \\
\hline
\end{tabular}

Results:

The cardiopulmonary bypass (CPB) time and the cross clamp (Cx) time, and the amount of used cryoprecipitate (Cryo),

fresh frozen plasma (FFP), platelet (PLT), erythrocyte suspension (ES) and the bleeding amount were significantly higher in the groups that stayed at the hospital for $>7$ days and at the intensive care unit (ICU) for $>2$ days $(p>0.05)$. In the univariate model, to predict the patients who might stay at the hospital for more than one week and who might

stay at the ICU for more than 3 days, we considered the significant efficacy of postoperative FFP, PLT, ES transfusion, bleeding amount, and the CPB time $(p<0.05)$. In the reduced multivariate model, however, we analyzed the significant-

independent efficacy of the postoperative FFP use to determine the patients who would stay at the hospital for more than one week and who would stay at the ICU for more than 3 days $(p<0.05)$

There was no significant correlation between the duration of ICU stay and age, BMI, and the levels of Hb, Htc, INR, BUN,

and creatinine, whereas there was a significant positive correlation between the Cx and CPB time, and the amouns of administered cryoprecipitate, FFP, platelet, ES and the bleeding amount $(p<0.05)$.

Table 2: Comparison of transfusion rate, bleeding amount and CPB time in uni and multi variate models

\begin{tabular}{|c|c|c|c|c|c|c|c|c|}
\hline & \multicolumn{3}{|c|}{ Univariate model } & \multicolumn{5}{|c|}{ Multivariate reduced model } \\
\hline & $\begin{array}{l}\text { Odds } \\
\text { Ratio }\end{array}$ & $\begin{array}{l}\text { 95\% Confidence } \\
\text { Interval }\end{array}$ & p & $\begin{array}{l}\text { Odds } \\
\text { Ratio }\end{array}$ & $\begin{array}{r}95 \% \mathrm{C} \\
\text { In }\end{array}$ & enf & $\begin{array}{l}\text { dence } \\
\text { al }\end{array}$ & p \\
\hline Postoperative FFP & 1,404 & $1,144-1,723$ & 0,001 & 1,404 & 1,144 & $\theta$ & 1,723 & 0,001 \\
\hline Postoperative PLT & 1,269 & $1,073-1,501$ & 0,005 & & & & & \\
\hline Postoperative ES & 1,314 & $1,103-1,564$ & 0,002 & & & & & \\
\hline Bleeding amount & 1,002 & $1,001-1,030$ & 0,049 & & & & & \\
\hline CBP time & 1,008 & $1,001-1,014$ & 0,027 & & & & & \\
\hline
\end{tabular}

Conclusion:

We have concluded that increased use of blood products was associated with the Cx and CPB time and prolonged duration of hospital and ICU stays. In open cardiac surgeries, the use

of blood products due to bleeding was identified as a predictor for a stay longer than 3 days at the ICU and longer than 7 days at the hospital.

\section{References:}

I. Task Force on Patient Blood Management for Adult Cardiac Surgery of the European Association for Cardio-Thoracic Surgery (EACTS) and the European Association of Cardiothoracic Anaesthesiology (EACTA), Boer C, Meesters MI, Milojevic M, Benedetto U, Bolliger D, von Heymann C, Jeppsson A, Koster A, Osnabrugge RL, Ranucci M, Ravn HB, Vonk ABA, Wahba A, Pagano D. 2017 EACTS/EACTA Guidelines on patient blood management for adult cardiac surgery. J Cardiothorac Vasc Anesth 201 8;32:88- 120 2. Kozek-Langenecker SA, et

al. Management of severe perioperative bleeding: guidelines from the European Society of Anaesthesiology: First update 2016. Eur J Anaesthesiol 2017;34:332-395. 